\title{
Testing pigeon control efficiency by different methods in urban industrial areas, Hungary
}

\author{
Thabang Rainett Teffo ${ }^{1}\left[\right.$ - Gergő Fuszonecker ${ }^{1} \cdot$ Krisztián Katona $^{1}$
}

Received: 6 May 2020 / Accepted: 2 November 2021 / Published online: 16 November 2021

(c) The Author(s) 2021

\begin{abstract}
The development of cities and urban sprawl has made room for wildlife inhabiting human environments. Among birds, feral pigeons (Columba livia domestica) are often present in large numbers in the cities. Problems related to pigeon occurrence result in economic loss and health issues for humans. There are different methods of controlling pigeon populations in urban areas. In this study, we compared three techniques that can be used for pigeon pest control. In two urban industrial sites in Hungary, we used trapping, falconry (in both Study Area 1 and 2) and mist-netting (only in Study Area 2) to remove pigeons. We compared the effectiveness and limitations of each method. Our results show that over 105 days in Study Area 1, we managed to remove 173 individual pigeons. We did not find a significant difference between the effectiveness of trapping or falconry. In Study Area 2, the overall number of pigeons removed was 1412 over a period of 150 days. There, we managed to catch significantly more birds by netting than by trapping or falconry, but the latter two did not differ statistically. We recommend a combination of techniques for pigeon control. Mist-netting can be the most effective way for direct pigeon removal, whereas trapping is an easier but less efficient method to catch pigeons. Falconry is the least efficient in pigeon catching and requires the most investments, but the bird of prey may chase the pigeons away for a short time.
\end{abstract}

Keywords Columba livia domestica $\cdot$ Urban industrial area $\cdot$ Trapping $\cdot$ Falconry $\cdot$ Netting

\section{Introduction}

The development of cities has made room for urbanising wildlife across the world (Hunter 2007; Soulsbury and White 2015), causing wildlife species to experience and inhabit human habitats (Magle et al. 2012). Since the 1900s, cities and urban areas have grown rapidly (Su et al. 2011) mainly due to human movement from rural areas to cities (Li et al. 2018; McKinney 2002).

In an urbanised world, understanding and controlling the indirect impacts of cities is a big challenge to biodiversity conservation (Puppim de Oliveira et al. 2011; Xu et al. 2018). The existence of wild and feral animal species within urban areas can also cause several ecological, economic and sociological problems (Haidar et al. 2017). Urban areas are

Thabang Rainett Teffo

thabang.jeany@gmail.com

1 Department of Wildlife Biology and Management, Institute for Wildlife Management and Nature Conservation,

Hungarian University of Agriculture and Life Sciences, Páter

Károly street 1, Gödöllő H-2100, Hungary hubs to extended industrial activity that include airports, mines and factories. These massive industries consist of structures that can provide a home for wildlife species ranging from small mammals and birds to large mammals resulting in variable damages (Fu et al. 2016).

It is common to find large populations of birds within cities and industrial areas across the world. Feral pigeons (Columba livia domestica) are one of the species with the highest numbers that co-exist with human populations within cities (Haag-Wackernagel and Moch 2004). They usually breed in crevices or on window ledges, under bridges and on roof tops. Pigeons are resident birds that have an impact on buildings: using such structures as both nesting and roosting sites in large numbers and often becoming the dominant species in wintering urban bird assemblages (Ciach and Fröhlich 2016). They also inhabit industrial areas such as warehouses or airports (Matyjasiak 2008). This is because the conditions in urban industrial areas are often beneficial for pigeons and other bird species. Urban habitats and their structures provide a vast variety of resources, e.g. humans frequently feed pigeons (Rose et al. 2006). 
Pigeons can cause several kinds of damage (Lawson 1979). The accumulation of their droppings can have a serious socio-economic impact in urban communities. These droppings cause damage to the structural materials (stone constructions, roofs, ceilings, machinery, ventilation systems etc.) in urban industrial areas (Gomez-Heras et al. 2004). The damage can also create slipping and falling hazards to workers, increased maintenance of materials, and human health problems, as pigeons are often associated with mycotic diseases, viruses, bacteria, endo- and ectoparasites (Haag-Wackernagel and Moch 2004; Phan et al. 2013).

There are several solutions that can be applied to remove pigeons, which are considered pests in the industrial environment, in order to mitigate the damage that they cause (Fitzwater 1988). As a primary option, allowing pigeons to settle in an industrial area should ideally be prevented. Buildings could be designed to maintain a pigeon-free environment and not to attract them (Haag-Wackernagel and Geigenfeind 2008). If this has not been taken into account previously, suitability of the habitat for pigeons should be reduced through manipulation of their required resources and conditions. We can limit the accessibility of roost and nest sites by applying exclusions such as anti-bird netting or decrease their attractiveness by using a variety of bird scaring techniques, visual, audio, chemical or mechanical solutions; and finally, birth control, trapping and culling could also be considered (Dobeic et al. 2011; Giunchi et al. 2007; Hutton and Dobson 1993).

In this study, the authors examine falconry, live box-trapping and mist-netting as three methods to control pigeon populations in urban industrial sites. Falconry is the hunting of wild animals in their natural state and habitat using a trained bird of prey (Joseph 2006). However, falconry can be time consuming and requires the falconer's effort and care (food, rest time and reproduction) for his birds. Raptors also go through moulting, which has a negative impact on flight performance (Zuberogoitia et al. 2018). Trapping can also be a slow and labour-intensive process depending on the target species (Fitzwater 1988). In the case of pigeons, the use of live box-traps can be less labour intensive as large numbers of traps are not required and do not need round the clock monitoring. However, they must be checked every few days. Baiting can increase trap efficiency (Baskett et al. 1993). According to Marques et al. (2013), mist-netting is the most effective as we can catch a higher number of birds more efficiently. However, netting is time consuming and labour intensive, requiring specific expertise and a continuous presence at the site to immediately remove animals caught in the nets.

When comparing the three methods, we hypothesised that the largest number of pigeons could be removed by mistnetting, since in our case it is an active intervention: disturbing and forcing the pigeons to fly into the net. Trapping is a passive solution to pigeon catching: by attracting them with bait and not chasing them. So, we expected it to be slightly less efficient than netting per time unit. We supposed that falconry would be the least efficient direct removal of pigeons from urban factories since the catching rate can be highly variable among individual raptors.

We also hypothesised that there would be a decrease in the daily number of removed pigeons during the period of the investigation due to the expected gradual decline of local pigeon population as the result of our intervention.

\section{Materials and methods}

\section{Study areas}

The study took place in two large industrial sites in Hungary. One belongs to a plastic assembling factory and the other to a brick manufacturing firm. They both have a conflict with pigeons within their premises that cause various problems.

The plastic manufacturing factory (Study Area 1) is in the capital city of Hungary, Budapest. The unit is situated on the east side of the city and the premises cover an area of 10 ha. More than 100 employees work there.

The site of the brick manufacturing firm (Study Area 2) is within a distance of $40 \mathrm{~km}$ from Budapest. The industrial area is fenced and covers an area of 12 ha. The company has approximately 80 staff members.

In Study Area 1, there is one building of three floors, whereas in Study Area 2 there are two ground floor buildings. Both study areas have experienced problems with massive pigeon populations that have flocked within the premises. These birds nest and roost on the frames and balconies of the buildings. The pigeon droppings erode manufacturing materials and the structures of factory buildings and may cause health problems to workers.

At the beginning of each month during the study (from 4th January 2018 in Study area 1 and from 2nd April 2018 in Study Area 2), the number of pigeons seen in the industrial area and flying around the premises was roughly estimated to check the effectiveness of the pigeon removal program. Pigeons were counted by three observers simultaneously from the corners of the outer yard and from the entrance within the building. We moved them out of their hiding places using a trained bird of prey to disturb them. From each counting point, the observation lasted until all visible pigeons were counted (i.e. 10 to $15 \mathrm{~min}$ ). The estimation was based on a count of blocks of flocks including 10,50 or 100 birds depending on the total number of the individuals. 


\section{Methods of pigeon removal}

We utilised three different methods of pigeon control. In both study areas, two methods (falconry and live trapping) were used simultaneously each time the industry premises were visited. However, netting was only conducted at Study Area 2. Erection of the net was impossible in Study Area 1 due to the lack of large open spaces within the buildings. We collected data over a period of 3 and a half months (105 days, from January to April 2018) in Study Area 1, and 5 months (150 days, April to August 2018) in Study Area 2. Our aim was not to compare the results of two areas, but to use several areas to evaluate the effectiveness of different techniques.

\section{Falconry}

Four raptor birds were used in our investigations: an adult (2 years old) goshawk (Accipiter gentilis), an adult peregrine falcon (Falco peregrinus), and an adult and a young (0.5 years old) Harris's hawk (Parabuteo unicinctus). The birds were trained by a professional falconer how to hunt, be sociable around humans, and follow the hunting instructions of the falconer. On the same days, three or four individuals of these birds were involved in the work. They were brought seven times per month to Study Area 1, and between 12 and 15 times per month in Study Area 2 (altogether 24 and 65 hunting events, respectively). One of the birds was released within the premises and allowed to chase or capture pigeons for a period of time until replaced by another raptor. Caught pigeons were taken from the raptors and alternative food was provided. Altogether six hours per day between 09h00 and $15 \mathrm{~h} 00$ was covered by falconry. This way we could start after sunrise but finish before the pigeons had time to find their roosting place for night.

\section{Trapping}

A single metal live box collector trap of the dimensions of $1 \mathrm{~m} \times 2 \mathrm{~m} \times 0.5 \mathrm{~m}$ with one door was used for trapping the pigeons. It was placed on the roof of the building or in the attic near an exit/entry opening. One half of the top of the trap was covered providing shelter. It was baited with corn and mixed grain food. Water was also provided within the trap. The trap was heated to prevent freezing in the cold winter period. The trap was put out in the study areas on the first day of the study session and was kept activated for the entire period. However, during the night pigeons did not move around in the areas, so they only entered the trap during the day. The trap was checked and the pigeons removed from it on the same days as the falconry was carried out (on average 4 and 2.35 days lasted between two consecutive occasions in the two areas, respectively). On those days, captured pigeons were removed just before the falconry began. During the period when raptor birds chased the pigeons, the trap was entirely covered with a jute fabric cover, making trapping impossible. Therefore, during the daylight periods from the end of one falconry occasion until the beginning of the next one, there was a continuous opportunity to trap pigeons (meaning 81 and 85 trapping days, respectively).

\section{Mist-netting}

In Study Area 2, the netting method was also used. The size of the net was $20 \mathrm{~m} \times 20 \mathrm{~m}$ and was fixed vertically to the transport and escape routes of the pigeons within the building. The mesh size was $5 \mathrm{~cm} \times 5 \mathrm{~cm}$, into which the head of the pigeon easily fitted, but could swiftly be removed by researchers directly after the capture. The net is made of a specialised Teflon material that does not cause injury to the birds even if they fly into it at high speeds. The net was erected once a week; 21 days in total. No bait was used for this method. After sunset, when the pigeons had already rested in complete darkness, they were disturbed with light, noise and the use of a telescopic fishing rod. The pigeons reacted to the disturbance by trying to escape, and some individuals from the exploding flock flew into the net. This procedure lasted anything from $1.5 \mathrm{~h}$ to 3 or $4 \mathrm{~h}$, continuing until the pigeons found an exit or a place to hide again. At the end of every session, the net was removed.

There was no interference between the three methods as falconry was performed during the day, while netting was performed overnight. During falconry, the trap was covered, and during the night pigeons did not enter the trap to take the bait as they are not nocturnal.

\section{Ethical statements}

Since feral pigeons are considered a serious pest, solutions for translocation and the release of large numbers of caught urban pigeons was unrealistic despite being the most humane solution. Moreover, these birds are able to find their way back home from hundreds of kilometres away.

We performed pigeon thinning and related examinations in full compliance with Hungarian legislation and EU directives, and with the consent, approval and support of the competent state body, hunting and nature conservation authority. The required permissions for using raptor birds and catching pigeons in these areas were obtained by Gergó Fuszonecker.

Pigeons caught in any way were transported in compliant transport crates. They were then killed in a humane manner (according to food industry regulations for poultry slaughter). After veterinary examination, the carcasses were frozen. Finally, meat from the dead birds was used as food for birds in the falcon breeding program. Pigeon has a good quality meat with a high protein content and perfectly suited to 
feeding birds of prey. Additionally, if a ringed carrier pigeon was found, the owner was notified, and the bird was returned alive.

\section{Data analysis}

To analyse data for both study areas, the Graphpad Prism 6 statistical software was used. The normality of the datasets was tested using Shapiro-Wilk normality test (Shapiro and Wilk 1965). One-way ANOVA with Tukey-Kramer post hoc test or Kruskal-Wallis test with Dunn's multiple comparisons test was used to analyse temporal changes of caught individuals within methods. Wilcoxon matched-pairs signed rank test or Friedman's ANOVA test with Dunn's multiple comparisons test was conducted to test differences between the daily number of pigeons removed by different methods (Hazra and Gogtay 2016).

\section{Results}

\section{Study area 1}

At Study Area 1, there was no significant difference in the daily number of pigeons removed by trapping and falconry (Wilcoxon matched-pairs signed rank test: $N=24, W=48$; $p=0.48$ ) (Fig. 1). The overall number of pigeons removed by these two methods was 173 (111 and 62 individuals by trapping and falconry, respectively).

We found a significant temporal difference among the consecutive months in the daily number of pigeons caught by falconry (one-way ANOVA: F $(3,20)=4.01, p=0.02$ ), where the value measured in March was significantly lower than in January, showing a steady decrease by that time; however, it was also statistically lower than in April, reflecting a subsequent increase in the trend.
There was, however, no such temporal difference in the monthly trapping data (Kruskal-Wallis test: $H=7.71$, $p=0.052$ ), although the $\mathrm{p}$ value was close to the conventional significance level.

Therefore, neither of our hypotheses was statistically supported in Study Area 1.

\section{Study area 2}

Conversely, in Study Area 2, a significant difference was found among the daily numbers of caught birds using the three different methods (Friedman's ANOVA: $\chi^{2}(2)=36.86$, $p<0.0001$ ) (Fig. 2). We managed to remove the highest number of pigeons by netting and the least by falconry. Netting was significantly more effective than either of the other methods (Dunn's multiple comparisons test: $p<0.001$ ), but trapping and falconry did not differ from each other statistically. In Study Area 2, we managed to remove 1412 pigeons in total $(686,581$ and 145 individuals by netting, trapping and falconry, respectively).

Moreover, we also revealed a significant difference between the five months in the daily number of pigeons caught by trapping (Kruskal-Wallis test: $H=19.85$, $p<0.001)$. We trapped substantially more pigeons in June than in April (Dunn's multiple comparisons test: $p<0.001$ ), but no difference was found for the other pairings of monthly trapping values.

However, no significant difference was found in the daily number of pigeons caught by falconry (Kruskal-Wallis test: $H=2.25, p=0.69$ ) or removed by netting (Kruskal-Wallis test: $H=3.64, p=0.46$ ) during the months the experiment took place.

Considering our expectations, the predicted differences in the effectiveness of the methods were present in Study Area 2 , but not the decline in the daily catching rate.

According to our rough visual estimations, the number of pigeons dropped from around 175 to 40 in Study Area 1
Fig. 1 Comparison between two methods of pigeon removal at Study Area 1 over a period of four months

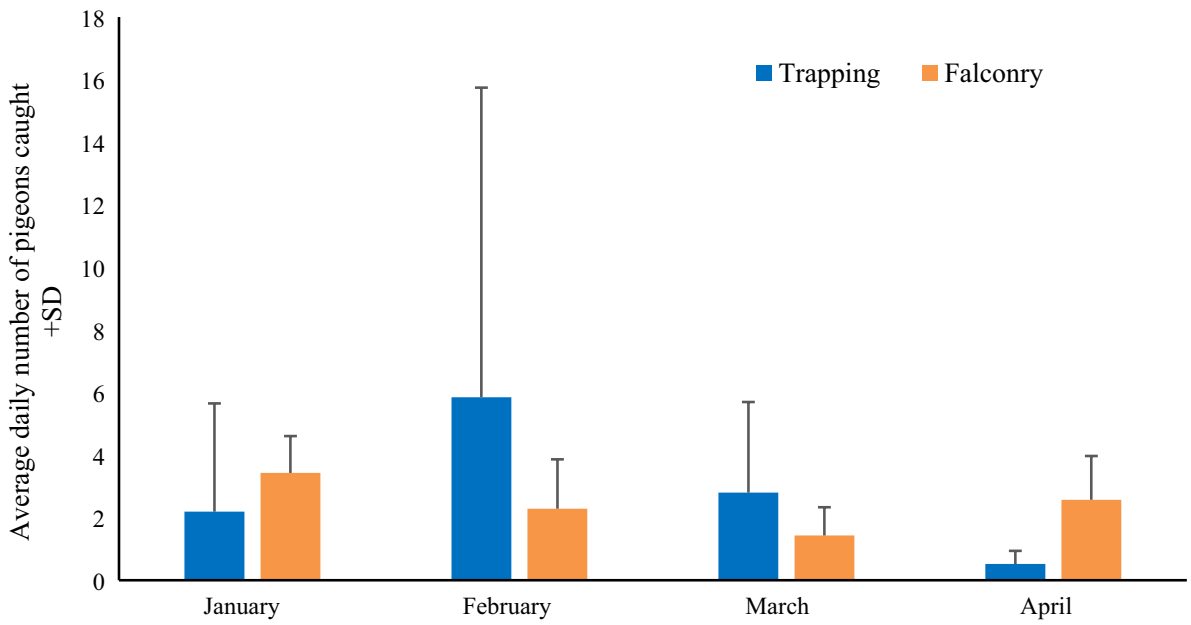


Fig. 2 Comparison between three methods of pigeon removal at Study Area 2 over a period of five months

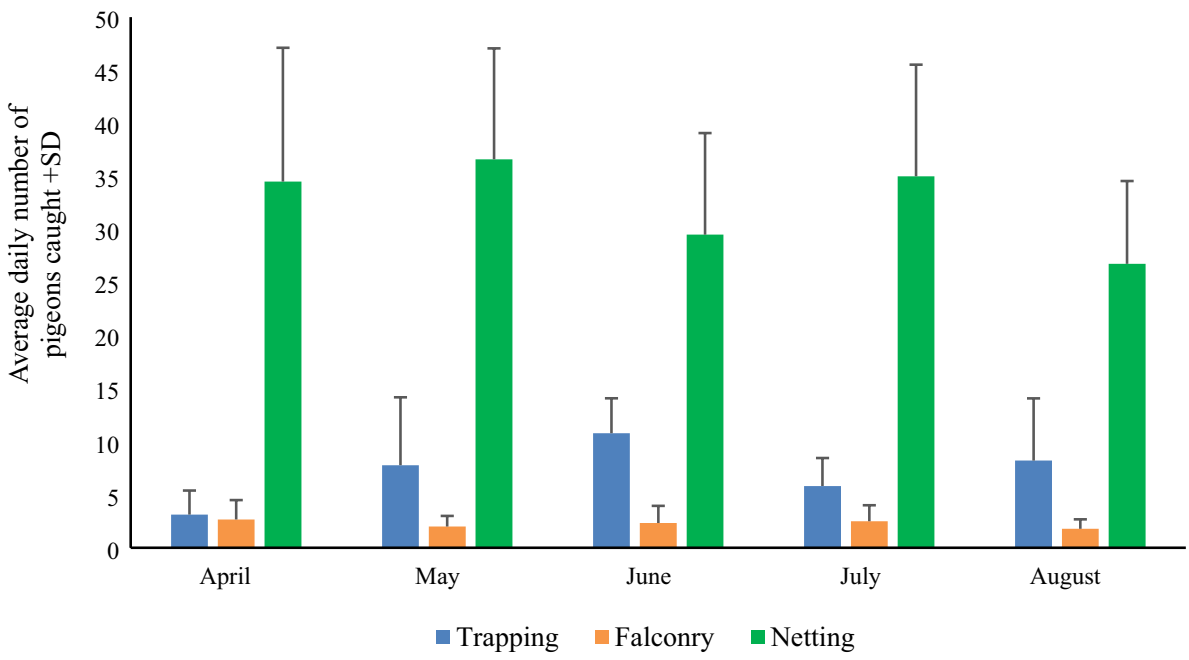

and from approximately 1000 to 250 in Study Area 2, during the investigation period of 105 and 150 days, respectively.

\section{Discussion}

We found differences in the effectiveness of used methods to remove pigeons from study areas with mist-netting being the most effective method of pigeon removal, followed by trapping and then falconry. Although only netting showed statistical differences from the other two methods, the absolute number of birds caught by trapping was also higher than birds caught by falconry in both areas.

Relatively safe roosting and nesting places and stable food and water resources are important survival factors for feral pigeons; the industrial zones, including the investigated factories, provide such conditions. Using anti-bird protection nets and wires to fence areas against pigeons can be very expensive in large industrial buildings. Falconry can serve as a solution to make the area less safe for the pigeons by creating a landscape of fear (spatial variation in predation risk as perceived by prey across their foraging or home range, see Laundré et al. 2010). Based on this theory, we can expect that frequent chasing of pigeons by their primary avian predator, even if it often does not lead to capturing, can be an adequate intervention. Falconry can be used as a basic solution to cause an unpredictable threat to resident birds, which may lead to temporary or permanent abandonment of the area. However, falconry as a complex practice has various limitations, including the need for trained and licensed falconers with a number of individual birds of prey. The raptors, which can be rare or a protected species and difficult to acquire, also require special feeding, training, and housing care (Erickson et al. 1990). It is also likely that the maximum number of pigeons caught by the birds of prey per day is determined by the upper limit for how many pigeons a falcon or hawk can catch.

Since pigeons are able to hide from birds of prey within industrial buildings, additional removal methods should also be taken into consideration. Live trapping of pest animals can be an effective method of their population control in practice (Chiron and Julliard 2013). Providing the elementary nutritional resources, i.e. their preferred food types, as bait, as well as water, we can easily attract pigeons into the trap. Although sufficient expertise is required to select the appropriate location for the trap and set it up, the trap does not require the presence of a person. Other than the time taken to check the traps regularly for caught birds, this method is more convenient relative to the other two. Trapping as a method of population control has various assumptions, but animals may or may not become trap shy (Hammond 2018). We can argue that during the first month the pigeons were unfamiliar with the foreign object (trap) in their territory. However, as the trap remained in their area, they got used to it, and baited with various food sources, it initially served as an attractive object for many pigeons. They started using the trap more intensively in the second month (and mainly in the third month in Study Area 2), when larger quantities of pigeons were removed in absolute number. Later, mainly in Study Area 1, fewer pigeons were removed by trapping in absolute number, which may have been due to two parallel processes. It is possible that the boldest pigeons had already been removed during the first months of the study, leading to an increased proportion of trap shy individuals in the population. It is also possible those remaining pigeons identified the capture of their conspecifics and decided to not enter the trap, as pigeons have a significant cognitive functioning (Darby et al. 2018).

Whereas trapping is a relatively passive method, where birds enter traps "of their own free decision", mist-netting of pigeons in our study was an active intervention; 
disturbing and driving the pigeons into the net. This latter method is very efficient in removing large numbers of pigeons within a short time period, as supported by our results. However, it is important to note that in small local pigeon populations falconry and trapping might also be effective, if combined, as found in Study Area 1 where the two methods reduced the pigeon population by approx. $80 \%$. Although mist-netting was found to be the most effective technique in our study, this method has limitations (Keyes and Grue 1982). The most important thing worth noting in this context is the requirement of an open space of adequate size in which the net can be erected, as well as the need for expertise to drive the pigeons from the structures of the building into the net without harm.

\section{Conclusion for future biology}

Feral pigeon populations often inhabit urban industrial areas, where it is of paramount importance to control populations in order to mitigate the problems they cause. Our results show that with effective interventions, despite the possibility of immigration and reproduction, we still experienced a population decline, confirming the effectiveness of the methods we used.

Our study highlighted that mist-netting is a highly efficient way of removing pigeons in urban factories within a short time. Although live trapping of pigeons by box-trap was not found to be as effective as netting when comparing the daily capture rates, it can be the simplest technique and using more traps can increase the effectiveness of this method. Falconry can reduce the presence of pigeons by creating fear in them. Since the characteristics of the areas can influence the utility and impact of the control methods, as shown by different results between our two sites, a combination of the methods is recommended for greater overall efficiency, in a decreasing ranking order of mistnetting, trapping and then falconry.

\footnotetext{
Acknowledgements This research project was supported by international scholarships research fund of the Department of Higher Education and Training (DHET), South Africa and Stipendium Hungaricum Scholarship. The authors would like to extend their gratitude to the two factories for allowing us to use their premises as our study sites. We thank Ms. Tawani Naude, Ms. Tamsyn van Gelderen and Prof. C.J. van Gelderen for improving the English language of our manuscript. We acknowledge the African Wildlife Economy Institute (AWEI) and the Doctoral School of Animal Biotechnology and Animal Science of the Hungarian University of Agriculture and Life Sciences (MATE) for accepting Thabang Teffo as their postgraduate fellow and offering him professional support.
}

Funding Open access funding provided by Hungarian University of Agriculture and Life Sciences.

\section{Declarations}

Conflict of interest The authors declare that they have no conflict of interest.

Open Access This article is licensed under a Creative Commons Attribution 4.0 International License, which permits use, sharing, adaptation, distribution and reproduction in any medium or format, as long as you give appropriate credit to the original author(s) and the source, provide a link to the Creative Commons licence, and indicate if changes were made. The images or other third party material in this article are included in the article's Creative Commons licence, unless indicated otherwise in a credit line to the material. If material is not included in the article's Creative Commons licence and your intended use is not permitted by statutory regulation or exceeds the permitted use, you will need to obtain permission directly from the copyright holder. To view a copy of this licence, visit http://creativecommons.org/licenses/by/4.0/.

\section{References}

Baskett TS, Sayre MW, Tomlinson RE (1993) Ecology and management of the mourning dove. Stackpole Books, Harrisburg PA

Chiron F, Julliard R (2013) Assessing the effects of trapping on pest bird species at the country level. Biol Conserv 158:98-106. https://doi.org/10.1016/j.biocon.2012.08.001

Ciach M, Fröhlich A (2016) Habitat type, food resources, noise and light pollution explain the species composition, abundance and stability of a winter bird assemblage in an urban environment. Urban Ecosyst 20:547-559. https://doi.org/10.1007/ s11252-016-0613-6

Darby KP, Castro L, Wasserman EA, Sloutsky VM (2018) Cognitive flexibility and memory in pigeons, human children, and adults. Cognition 177:30-40. https://doi.org/10.1016/j.cognition.2018. 03.015

Dobeic M, Pintarič Š, Vlahović K, Dovč A (2011) Feral pigeon (Columba livia) population management in Ljubljana. Vet Arhiv 81:285-298

Erickson WA, Marsh RE, Salmon TP (1990) A review of falconry as a bird-hazing technique. Proceedings of the Fourteenth Vertebrate Pest Conference 25. https://digitalcommons.unl.edu/vpc14/25

Fitzwater WD (1988) Solutions to urban bird problems. Proceedings of the Thirteenth Vertebrate Pest Conference. 52. https://digitalcom mons.unl.edu/vpcthirteen $/ 52$

Fu Q, Wang N, Shen M, Song N, Yan H (2016) A study of the site selection of a civil airport based on the risk of bird strikes: The case of Dalian, China. J Air Transp 54:17-30. https://doi.org/10. 1016/j.jairtraman.2016.03.016

Giunchi D, Baldaccini NE, Sbragia G, Soldatini C (2007) On the use of pharmacological sterilisation to control feral pigeon populations. Wildl Res 34:306-318. https://doi.org/10.1071/WR06153

Gómez-Heras M, Benavente D, Álvarez De Buergo M, Fort R (2004) Soluble salt minerals from pigeon droppings as potential contributors to the decay of stone based cultural heritage. Eur J Miner 16:505-509. https://doi.org/10.1127/0935-1221/2004/0016-0505

Haag-Wackernagel D, Geigenfeind I (2008) Protecting buildings against feral pigeons. Eur J Wildl Res 54:715-721. https://doi. org/10.1007/s10344-008-0201-z

Haag-Wackernagel D, Moch H (2004) Health hazards posed by feral pigeons. J Infect 48:307-313. https://doi.org/10.1016/j.jinf.2003. 11.001

Haidar I, Alvarez I, Prévot AC (2017) Mathematical modeling of an urban pigeon population subject to local management strategies. 
Math Biosci 288:71-83. https://doi.org/10.1016/j.mbs.2017.03. 002

Hammond PS (2018) Mark-recapture. In: Würsig B, Thewissen JGM, Kovacs KM (eds) Encyclopedia of marine mammals, 3rd edn. Academic Press, pp 580-584. https://doi.org/10.1016/B978-0-12804327-1.00168-0

Hazra A, Gogtay N (2016) Biostatistics series module 3: comparing groups: numerical variables. Indian J Dermatol 61:251-260. https://doi.org/10.4103/0019-5154.182416

Hunter P (2007) The human impact on biological diversity. How species adapt to urban challenges sheds light on evolution and provides clues about conservation. EMBO Rep 8:316-318. https:// doi.org/10.1038/sj.embor.7400951

Hutton TC, Dobson J (1993) The control of feral pigeons: an independent approach. Struct Surv 11:159-167. https://doi.org/10.1108/ 02630809310028521

Joseph V (2006) Raptor medicine: an approach to wild, falconry, and educational birds of prey. Vet Clin Exot Anim 9:321-345. https:// doi.org/10.1016/j.cvex.2006.03.007

Keyes BE, Grue CE (1982) Capturing birds with mist nets: a review. North Am Bird Bander 7:2-14

Laundre JW, Hernandez L, Ripple WJ (2010) The landscape of fear: ecological implications of being afraid. Open Ecol J 3:1-7

Lawson HM (1979) Feral pigeon damage to field beans. Ann Appl Biol 92:153-157. https://doi.org/10.1111/j.1744-7348.1979.tb02968.x

Li Y, Jia L, Wu W, Yan J, Liu Y (2018) Urbanization for rural sustainability - rethinking China's urbanization strategy. J Clean Prod 178:580-586. https://doi.org/10.1016/j.jclepro.2017.12.273

Magle SB, Hunt VM, Vernon M, Crooks KR (2012) Urban wildlife research: past, present, and future. Biol Conserv 155:23-32. https://doi.org/10.1016/j.biocon.2012.06.018

Marques JT, Pereira MJR, Marques TA, Santos CD, Santana J, Beja P, Palmeirim JM (2013) Optimizing sampling design to deal with mist-net avoidance in Amazonian birds and bats. PLoS ONE 8:e74505. https://doi.org/10.1371/journal.pone.0074505

Matyjasiak P (2008) Methods of bird control at airports. In: Uchmański J (ed) Theoretical and applied aspects of modern ecology. Cardinal Stefan Wyszyński University Press, Warsaw, pp 171-203
McKinney ML (2002) Urbanization, biodiversity, and conservation: the impacts of urbanization on native species are poorly studied, but educating a highly urbanized human population about these impacts can greatly improve species conservation in all ecosystems. Bioscience 52:883-890. https://doi.org/10.1641/00063568(2002)052[0883:UBAC]2.0.CO;2

Phan TG, Vo NP, Boros Á, Pankovics P, Reuter G, Li OTW, Wang C, Deng X, Poon LLM, Delwart E (2013) The viruses of wild pigeon droppings. PLoS ONE 8:e72787. https://doi.org/10.1371/journal. pone. 0072787

Puppim de Oliveira JA, Balaban O, Doll CNH, Moreno-Peñaranda R, Gasparatos A, Iossifova D, Suwa A (2011) Cities and biodiversity: perspectives and governance challenges for implementing the convention on biological diversity (CBD) at the city level. Biol Conserv 144:1302-1313. https://doi.org/10.1016/j.biocon. 2010.12.007

Rose E, Nagel P, Haag-Wackernagel D (2006) Spatio-temporal use of the urban habitat by feral pigeons (Columba livia). Behav Ecol Sociobiol 60:242-254. https://doi.org/10.1007/ s00265-006-0162-8

Shapiro SS, Wilk MB (1965) An analysis of variance test for normality (complete samples). Biometrika 52:591-611. https://doi.org/10. 1093/biomet/52.3-4.591

Soulsbury CD, White PCL (2015) Human-wildlife interactions in urban areas: a review of conflicts, benefits and opportunities. Wildlife Res 42:541-553. https://doi.org/10.1071/WR14229

Su S, Jiang Z, Zhang Q, Zhang Y (2011) Transformation of agricultural landscapes under rapid urbanization: a threat to sustainability in Hang-Jia-Hu region, China. Appl Geogr 31:439-449. https://doi. org/10.1016/j.apgeog.2010.10.008

Xu X, Xie Y, Qi K, Luo Z, Wang X (2018) Detecting the response of bird communities and biodiversity to habitat loss and fragmentation due to urbanization. Sci Total Environ 624:1561-1576. https://doi.org/10.1016/j.scitotenv.2017.12.143

Zuberogoitia I, Zabala J, Martínez JE (2018) Moult in birds of prey: a review of current knowledge and future challenges for research. Ardeola 65:183-207. https://doi.org/10.13157/arla.65.2.2018.rp1 